\title{
Malignant transformation in vestibular schwannoma: report of a single case, literature search, and debate
}

\author{
Case report \\ Charalampos Seferis, M.D., ${ }^{1}$ Michael Torrens, F.R.C.S., ${ }^{1}$ \\ Chryssa Paraskevopoulou, M.Sc., ${ }^{1}$ and Georgios Psichidis, M.D. ${ }^{2}$ \\ ${ }^{1}$ Gamma Knife Department, Hygeia Hospital, Athens; and ${ }^{2}$ Department of Neurosurgery, Diavalkaniko \\ Hospital, Thessaloniki, Greece
}

\begin{abstract}
Object. The significance of radiation in the induction of malignancy in vestibular schwannomas (VSs) after radiosurgery is unclear despite an increasing number of case reports. The authors describe a new case of verified malignant transformation in a vestibular schwannoma (MTVS) and provide a new evaluation of such cases previously reported in the literature.

Methods. A 46-year-old woman underwent subtotal resection of a right-sided VS in 2004. The histological characteristics of the lesion were typical and benign. In early 2007 Gamma Knife surgery (GKS) was performed to treat a residual enlarging remnant. The radiosurgery parameters included the following: target volume $3.5 \mathrm{~cm}^{3}$, prescription dose $12 \mathrm{~Gy}$, prescription isodose $45 \%$, maximum dose $26.7 \mathrm{~Gy}$, and coverage $97 \%$. At 2 years' follow-up the lesion was enlarged to $5.2 \mathrm{~cm}^{3}$, but by 5 years it had decreased to $2.3 \mathrm{~cm}^{3}$. Six months later the lesion was $8.4 \mathrm{~cm}^{3}$. Repeated surgery was performed, and a histological analysis revealed a malignant peripheral nerve sheath tumor. The case was further managed with repeated GKS performed in the spring of 2013. At that time, the radiosurgery parameters included the following: target volume $3.5 \mathrm{~cm}^{3}$, prescription dose $16 \mathrm{~Gy}$, prescription isodose $45 \%$, maximum dose 35.6 Gy, and coverage $91 \%$. This Gamma Knife Department has treated a total of 205 patients with VS (local incidence of MTVS $0.49 \%$ ). A search of the literature published up to and including 2013 was performed using PubMed as well as more informal search methods.

Results. This patient is the 29th reported case of MTVS after radiation therapy. Of these cases, $40.7 \%$ were patients with neurofibromatosis (NF). In those cases in which histology showed tumors with previously benign characteristics, totally conforming to the criteria for MTVS, the mean delay to malignant expression was 68 months (median delay 72 months). The authors also retrieved papers reporting 30 cases of malignant VS in patients who had not undergone radiation treatment. Five of those cases were malignant transformation of a benign entity, and in 4 of them histology had verified that the initial disease was benign. In those 4 cases, there was a mean delay to malignant expression of 7.2 months (median delay 8 months).

Conclusions. Despite more frequent reports of MTVS after radiation treatment recently, there has been no accurate quantification of the risk, except in patients with NF, in whom the incidence of malignancy is high in relation to the numbers treated. The present analysis indicates that the risk of malignancy over 20 years in cases in which no radiation treatment has occurred is $1.32-2.08$ per 100,000, and this risk decreases to $1.09-1.74$ per 100,000 if cases of $\mathrm{NF}$ are excluded. After radiation treatment, the overall risk over 20 years is 25.1 per 100,000 , and this risk decreases to 15.6 per 100,000 if cases of NF are excluded. Radiation treatment increases the risk by approximately 10 times in non-NF cases.

(http://thejns.org/doi/abs/10.3171/2014.7.GKS141311)
\end{abstract}

\section{KeY Words • stereotactic radiosurgery — Gamma Knife surgery • malignant transformation $\quad$ vestibular schwannoma}

$\mathrm{D}$ ESPITE more frequent reports of malignant transformation of vestibular schwannoma (MTVS) after radiation treatment over the last 5 years, ,2,10,13,22,

\footnotetext{
Abbreviations used in this paper: GKS = Gamma Knife surgery; MPNST = malignant peripheral nerve sheath tumor; MTVS = malignant transformation of vestibular schwannoma; NF = neurofibromatosis; NF2 = neurofibromatosis Type 2; SRS = stereotactic radiosurgery; VS = vestibular schwannoma.
}

$36,43,46,51,57,61,62$ the quantitated significance of this radiation induction has not been clarified, except in cases of neurofibromatosis Type 2 (NF2) in which the incidence of malignancy is high in relation to the number of patients treated..$^{5}$ An excellent population study of nearly 5000 cases from Sheffield, England, ${ }^{47}$ suggested that there was no increased rate of malignancy of any kind after radiosurgery, but naturally such a study will not detect events with a probability of less than 1:5000. 
Prompted by the occurrence in our department of a case of an MTVS that conformed fully to Cahan's criteria for radiation-induced tumors, ${ }^{7}$ we conducted a literature search to identify other cases and compiled a list significantly larger than previous reviews.

\section{Case Report}

A 46-year-old woman with no evidence of NF2 presented with impaired hearing in 2003, and in mid-2004 underwent subtotal resection of a right-sided vestibular schwannoma (VS). The histological characteristics of the tumor were benign. Postoperatively, the patient exhibited a House-Brackmann Grade IV facial paresis and had no residual hearing on the right side.

In 2007 a residual enlarging tumor remnant was noted on MR imaging and GKS was performed. The radiosurgery parameters at the time included the following: target volume $3.5 \mathrm{~cm}^{3}$, prescription dose $12 \mathrm{~Gy}$, prescription isodose $45 \%$, maximum dose $26.7 \mathrm{~Gy}$, coverage $97 \%$, Paddick Conformity Index 0.8, and Gradient Index 3.0. At the 2-year follow-up in 2009, MR imaging showed that the lesion had enlarged to $5.2 \mathrm{~cm}^{3}$, but by 2012 it had decreased to $2.3 \mathrm{~cm}^{3}$. Six months later, an MR imaging examination showed that the lesion had grown rapidly to $8.4 \mathrm{~cm}^{3}$. Repeated partial excision was performed, and a new histological analysis revealed a malignant peripheral nerve sheath tumor (MPNST) with MIB-1 positivity in $30 \%$ of the cells. Immunohistochemical analysis of the tumor cells showed a general positive reaction for vimentin and a focal positive reaction for S-100 protein, but negative reactions for CD56, CD34, EMA, and GFAP. The delay in onset from radiosurgical treatment to presentation of malignant transformation totaled 66 months.

In the spring of 2013 the surgical remnant was treated again with GKS. The radiosurgery parameters at that time were as follows: target volume $3.5 \mathrm{~cm}^{3}$, prescription dose $16 \mathrm{~Gy}$, prescription isodose $45 \%$, maximum dose 35.6 Gy, coverage 91\%, Paddick Conformity Index 0.7, and Gradient Index 2.8. In 2014, at the patient's 6-month follow-up examination, no change in the tumor was found, and no new cranial nerve or other neurological deficit had developed.

A literature search was performed using the terms malignant, transformation, radiosurgery, vestibular, acoustic, schwannoma, neuroma, and malignant peripheral nerve sheath tumor/MPNST on PubMed together with a search and cross-check using Google Scholar. In addition, detailed contents of the publications retrieved in the search were cross-checked, because in some instances the same cases were reported in more than one journal by different authors.

\section{Results}

A total of 59 cases of MPNST of the vestibular nerve were reported in the literature: 29 cases occurred after radiation treatment, 25 cases arose spontaneously, and 5 cases occurred after surgery for benign disease. The details of these cases are summarized in Tables 1-3. The two largest collected series reported previously included 23 cases $^{57}$ and 35 cases. ${ }^{32}$ Of the 29 cases of MPNST that occurred after radiation treatment, $11(40.7 \%)$ of 26 patients in whom there was available information suffered from NF (Table 1). The average patient age was 40.4 years; 14 patients were female, 10 were male, and gender was not stated for the remaining 5 patients. The histological appearance of the tumor was MPNST in 19 patients, triton tumor in 3 patients, rhabdomyosarcoma in 1 patient, and MPNST with sarcomatous differentiation in 4 patients. In 2 cases the histological type of lesion was not clarified, but the progression was clearly malignant. Twenty-six cases had been treated by stereotactic radiosurgery (SRS) and 3 others by other forms of radiation therapy. In only 9 cases had histology proved the tumor benign before radiation treatment was performed. In the other cases there was no biopsy or the histological findings were not recorded. The overall mean delay from radiation treatment to malignant expression was 85 months. In those cases with documented prior benign histological findings that totally conformed to Cahan's criteria, ${ }^{7}$ the mean delay from radiation treatment to malignant expression was 68 months. The criteria for malignant transformation, as originally outlined by Cahan et al., ${ }^{7}$ are as follows: 1) benign histological type must be proven before irradiation; 2) there must be a prolonged latency period, usually greater than 4 years, between radiation delivery and tumor development; 3 ) the tumor must arise in the irradiated field; 4) the tumor must be histologically distinct from the original tumor; and 5) the patient must not have a genetic predisposition to the development of cancer.

Of the 30 cases that occurred without previous radiation treatment, $5(17 \%)$ of 29 patients suffered from NF (Tables 2 and 3). Thirteen patients were female, 14 were male, and sex was not stated for 3 patients. The average age of these patients was 43.2 years in the 25 patients in whom malignancy occurred spontaneously and 59 years in the 5 cases of MTVS. The histological tumor appearance was MPNST in 23 patients, triton tumor in 4 patients, and MPNST with melanomatous differentiation in 3 patients. In 4 cases the histological findings had proved to be benign at some time before the malignant condition appeared, and in these cases the mean delay to malignant expression was 7.2 months.

The chronology of published reports on the various cases was analyzed by dates of publication, and the results are shown in Table 4. It is evident that the incidence of cases in the three 5-year periods beginning in the year 2000 (43 cases) is approximately 3 times greater than the incidence of cases in the three 5-year periods before 2000 (15 cases). The millennium year, 2000, occurred 10 years after significant numbers of radiosurgical treatments for VS began to be performed.

\section{Discussion}

The case that we have described represents the 9th reported case of MTVS after radiation treatment that conforms fully to Cahan's criteria and the 29th case of MPNST occurring after radiotherapy or radiosurgery.

The topic most in need of evaluation is the determi- 
TABLE 1: Malignant transformation following radiation treatment ${ }^{\star}$

\begin{tabular}{|c|c|c|c|c|c|c|}
\hline Authors \& Year & $\begin{array}{c}\text { Age (yrs), } \\
\text { Sex }\end{array}$ & NF & $\begin{array}{c}\text { Type of } \\
\text { RT }\end{array}$ & Histological Type & $\begin{array}{l}\text { Cahan } \\
\text { Criteria }\end{array}$ & $\begin{array}{c}\text { Latency } \\
\text { (mos) }\end{array}$ \\
\hline Akamatsu et al., 2010 & $67, \mathrm{~F}$ & no & SRS & MPNST & yes & 90 \\
\hline Bari et al., 2002 & $28, F$ & yes & SRS & MPNST & & 48 \\
\hline \multirow[t]{3}{*}{ Baser et al., 2000} & NS, NS & yes & SRS & MPNST & & NS \\
\hline & NS, NS & yes & SRS & MPNST & & NS \\
\hline & NS, NS & yes & SRS & MPNST & & NS \\
\hline Carlson et al., 2010 & $25, \mathrm{~F}$ & yes & SRS & triton & & 120 \\
\hline Comey et al., 1998 & $50, M$ & no & SRS & rhabdomyosarcoma & & 60 \\
\hline Demetriades et al., 2010 & $37, \mathrm{M}$ & no & SRS & MPNST & yes & 120 \\
\hline Hanabusa et al., 2001 & $51, F$ & no & SRS & sarcoma & yes & 6 \\
\hline Hasegawa et al., 2013 & NS, NS & NS & SRS & MPNST & & NS \\
\hline Ho \& Kveton, 2002 & $14, F$ & yes & SRS & NS & & 7 \\
\hline Kubo et al., 2005 & $55, \mathrm{M}$ & no & SRS & MPNST & & NS \\
\hline Maire et al., 2006/Markou et al., 2012 & $45, F$ & no & CRT & MPNST & & 231 \\
\hline McEvoy \& Kitchen, 2003 & $22, \mathrm{M}$ & yes & SRS & NS & & 24 \\
\hline Muracciole et al., 2004 & $61, F$ & no & SRS & triton & & 72 \\
\hline Newell \& Pollack, 2012 & $50, M$ & no & yes & MPNST & & NS \\
\hline Norén, 1998 & $18, \mathrm{~F}$ & yes & SRS & MPNST & & 60 \\
\hline Pollock et al., 1998 & NS, NS & NS & SRS & triton & & NS \\
\hline Puataweepong et al., 2012 & $34, F$ & no & SRS & MPNST & & 72 \\
\hline Scheithauer et al., 2009 & $32, \mathrm{M}$ & yes & CRT & MPNST & & 324 \\
\hline Schmitt et al., 2011 & $51, \mathrm{M}$ & no & SRS & sarcoma & & 87 \\
\hline Shin et al., 2002; Kurita 1997† & $26, F$ & no & SRS & MPNST & yes & 72 \\
\hline Tanbouzi Husseini et al., 2011 & $20, M$ & yes & SRS & MPNST & & 60 \\
\hline Thomsen et al., 2000 & $19, F$ & yes & SRS & sarcoma & yes & 72 \\
\hline Van Rompaey et al., 2009 & $53, F$ & no & SRS & MPNST & & 96 \\
\hline Wilkinson et al., 2004 & $53, \mathrm{M}$ & no & SRS & MPNST & yes & 48 \\
\hline Yanamadala et al., 2013 & $51, F$ & no & SRS & MPNST & yes & 60 \\
\hline Yang et al., 2010 & $74, \mathrm{M}$ & no & SRS & sarcoma & yes & 72 \\
\hline present case & $34, F$ & no & SRS & MPNST & yes & 72 \\
\hline
\end{tabular}

* CRT = conformal radiotherapy; NF = evidence of neurofibromatosis; NS = not stated; RT = prior exposure to radiation; SRS = stereotactic radiosurgery.

$\dagger \mathrm{Kurita} \mathrm{H}$, et al: Malignant transformation of a vestibular schwannoma after gamma knife radiosurgery. Poster presentation at the Third Congress of International Stereotactic Radiosurgery Meeting, Madrid, 1997.

nation of the significance of radiation in the induction of malignancy, which up to now has not been quantified precisely. With reported numbers of malignant VSs in the radiation-treated population being the same as the numbers of malignant VSs in the immensely larger, non-radiation-treated population, the effect of radiation is clear. However, there may be a relative tendency to report cases involving previous radiation treatment more frequently. It is inevitable that the conclusions of this paper depend on the accuracy and comprehensiveness of reporting.

The population incidence of VS has been calculated to be between 12 and 19 per million people per year. ${ }^{3,55}$ Assuming an even prevalence and an average world population of 6 billion between 1990 and 2014, the number of VSs that develop globally per year would range from 72,000 to 114,000 . In relation to the number of cases that have been reported, the chance of developing a spontane- ous malignancy over 20 years would be 30 in 1.44-2.28 million or between $1.32 \times 10^{-5}$ and $2.08 \times 10^{-5}$. If only the 25 non-NF cases are considered, the chance would be between $1.09 \times 10^{-5}$ and $1.74 \times 10^{-5}$.

In cases of VS treated by radiation the risk needs to be related to the total population treated. According to Leksell Gamma Knife Society (LGKS) reports, ${ }^{33}$ the total number of GKSs for VS reported worldwide between 1991 and 2012 was 70,353. A survey by the Acoustic Neuroma Association in 2012 showed that $39 \%$ of radiation treatments were fractionated and $61 \%$ were single fraction. ${ }^{1}$ If one postulates that the proportion of singlefraction treatments represents GKSs and the remaining treatments were delivered by other methods, and if one assumes that the ratio in the United States applies to the rest of the world, then the total number of patients with VS treated by radiation worldwide could be around 
Malignant transformation after radiosurgery

TABLE 2: Spontaneous occurrence of malignant vestibular nerve tumors

\begin{tabular}{|c|c|c|c|c|}
\hline Authors \& Year & Age (yrs), Sex & NF & $\mathrm{RT}$ & Histological Type \\
\hline Best, 1987 & $24, F$ & yes & none & triton \\
\hline Caporlingua et al., 2014 & $50, F$ & no & none & triton (?) \\
\hline Chen et al., 2008 & $62, \mathrm{~F}$ & no & none & MPNST \\
\hline Earls et al., 1994 & NS, NS & NS & NS & melanotic \\
\hline Gong et al., 2012 & $55, \mathrm{~F}$ & no & none & triton \\
\hline Gonzalez et al., 2007 & $43, \mathrm{~F}$ & no & NS & MPNST \\
\hline Gruber et al., 1994 & $61, \mathrm{~F}$ & no & none & MPNST \\
\hline Han et al., 1992 & $47, \mathrm{~F}$ & no & none & triton \\
\hline Harada et al., 2000 & $10, M$ & no & none & MPNST \\
\hline Hernanz-Schulman et al., 1986 & NS, child & no & none & MPNST \\
\hline Higami et al., 1998 & $45, \mathrm{~F}$ & yes & none & MPNST \\
\hline Hong et al., 2014 & $25, M$ & no & none & MPNST \\
\hline Karami et al., 2011 & $23, \mathrm{~F}$ & no & none & MPNST \\
\hline Kudo et al., 1983 & $54, \mathrm{M}$ & no & none & MPNST \\
\hline Kuzmik et al., 2013 & $73, \mathrm{~F}$ & no & none & MPNST \\
\hline Maeda et al., 1993 & $38, M$ & no & none & MPNST \\
\hline Matsumoto et al., 1990 & $54, \mathrm{M}$ & no & none & MPNST \\
\hline Miller et al., 1986 & $74, \mathrm{M}$ & yes (?) & none & melanotic \\
\hline Mrak et al., 1994 & $40, M$ & no & none & MPNST \\
\hline Saito et al., 2000 & $69, \mathrm{M}$ & no & none & melanotic \\
\hline \multirow[t]{3}{*}{ Scheithauer et al., 2009} & $32, \mathrm{M}$ & yes & none & MPNST \\
\hline & $26, F$ & no & none & MPNST \\
\hline & $5, M$ & no & none & MPNST \\
\hline Suresh et al., 2003 & NS, NS & yes & none & MPNST \\
\hline Wei et al., 2012 & $41, \mathrm{~F}$ & no & NS & MPNST \\
\hline
\end{tabular}

115,333. The overall risk of MPNST over 20 years is therefore 29 in 115,333 or $25.1 \times 10^{-5}$. If patients with NF are excluded from this analysis, there remain 18 patients whose MPNST was associated with radiation treatment, and thus the risk for malignant transformation in the absence of NF is accordingly $15.6 \times 10^{-5}$. This represents a 9 to 14 times increased probability of malignancy in relation to that spontaneous incidence of between $1.09 \times$ $10^{-5}$ and $1.74 \times 10^{-5}$.

An independent study in patients with NF revealed that in a population of 1348 patients with NF2, 106 would have received radiosurgery. ${ }^{5}$ Malignant transformation occurred in 5 of these cases. This corresponds to a risk of
$4717 \times 10^{-5}$, a substantially greater risk than that found in patients who do not have NF. We found a greater proportion of patients with NF in the group of patients treated with radiation, which is compatible with the increased susceptibility of NF cases to radiation.

There are certain other prominent differences between cases treated with radiation and cases not treated in this manner. The first is the delay or latency from diagnosis to malignant expression. In cases in which radiation was delivered, this is 68 months (in cases of initial benign disease confirmed by histology) or 85 months (in all cases) compared with 7.2 months in cases in which there was no radiation treatment and there was a prior histological diagnosis

TABLE 3: Malignant transformation of a benign entity

\begin{tabular}{|c|c|c|c|c|c|c|}
\hline Authors \& Year & $\begin{array}{l}\text { Age (yrs), } \\
\text { Sex }\end{array}$ & NF & RT & Histological Type & $\begin{array}{c}\text { Prior Benign } \\
\text { Histological Findings }\end{array}$ & $\begin{array}{l}\text { Latency } \\
\text { (mos) }\end{array}$ \\
\hline Gousias et al., 2010 & $64, \mathrm{M}$ & $\mathrm{N}$ & none & MPNST & no* & 120 \\
\hline McLean et al., 1990 & $75, M$ & $\mathrm{~N}$ & none & MPNST & yes & 11 \\
\hline \multirow[t]{2}{*}{ Scheithauer et al., 2009} & $67, \mathrm{M}$ & $\mathrm{N}$ & none & MPNST & yes & 9 \\
\hline & $56, \mathrm{M}$ & $\mathrm{N}$ & none & MPNST & yes & 7 \\
\hline Son et al., 2001 & $33, \mathrm{~F}$ & $\mathrm{~N}$ & none & MPNST & yes & 2 \\
\hline
\end{tabular}

* No histology report available, but MR imaging over 120 months clearly shows a benign process that progressed to malignant disease. 
of benign disease. This would suggest that the cases involving radiation treatment are showing the delay required by the Cahan criteria for malignant induction, whereas the cases without radiation treatment are already in the process of malignant expression. Table 1 shows that 2 cases involving radiation treatment ${ }^{20,25}$ had an insignificant delay, 6 months for 1 case and 7 months for the other, and therefore may not be cases of true malignant transformation due to radiation, even though one of these patient $\mathrm{s}^{20}$ had histologically defined benign disease before SRS.

In addition, the group of patients with previous radiation treatment contains a larger proportion of cases in which histology revealed a sarcomatous element $(8$ [29.6\%] of 27 cases) than the group with no previous radiation treatment (4 [13.3\%] of 30 cases). Sarcomatous differentiation is known to be associated with irradiation, and the overall incidence of post-irradiation sarcoma in patients who survive longer than 5 years following radiation therapy is approximately $0.1 \% .^{27}$ This pattern of sarcomatous change also suggests that the malignant progression is due to radiation, although it is appropriate to point out that the rate of malignancy after radiosurgery for VS is 10 times less than that expected after radiation treatment of peripheral bone or soft tissue. ${ }^{27}$

Finally, there is evidence from the chronology of publications (Table 4) that there has been a 3 -fold increase in case reports since the year 2000. If a delay period of 5 to 8 years, according to Cahan's criteria, is added to the decade of 1990, when significant numbers of radiosurgical treatments began to be performed, then an increase in reported cases of MTVS would be expected from 2000 onwards if radiation is a significant predisposing factor for malignant progression. As has been noted earlier, there may be a tendency to report MTVSs more readily than spontaneous malignant VSs. It could also be argued that the armamentarium and expertise of neuropathologists has improved together with a general explosion in the number of published medical papers. Nevertheless, the sudden change in the reported numbers of MTVSs after the year 2000 seems significant.

Although the available information clearly indicates that there is a real chance of malignant transformation due to SRS, both the medical community and patients should be reassured that the risk is very low. The calculations above enumerate the risk value as $15.6 \times 10^{-5}$ or $0.016 \%$ in the absence of NF. This compares favorably with a realistic mortality rate after craniotomy of between $1 \%$ and $2 \% .{ }^{9,49}$ Although there are a few smaller surgical series of selected cases in which there were no deaths, ${ }^{52}$ it is not re-

\section{TABLE 4: Cases of malignant VSs presenting over time}

\begin{tabular}{cc}
\hline Dates of Publication of MPNST Cases & No. of Cases Recorded \\
\hline $1983-1989$ & 4 \\
$1990-1994$ & 6 \\
$1995-1999$ & 5 \\
$2000-2004$ & 14 \\
$2005-2009$ & 11 \\
$2010-2014$ & 18 \\
\hline
\end{tabular}

alistic to expect a surgical series of 10,000 cases without some mortality, and this is the number of cases required for a comparative result.

\section{Conclusions}

Despite more frequent reports of MTVS after radiation therapy, there has been no previous accurate quantification of the risk, except in cases of NF in which the incidence of malignancy is high in relation to the numbers treated. The present review indicates that the risk of malignancy over 20 years in cases in which no radiation was used is $1.32-2.08$ per 100,000 , and this decreases to $1.09-$ 1.74 per 100,000 if cases of NF are excluded. The analysis of published cases reveals that after radiation treatment the overall risk over 20 years is 25.1 per 100,000 , and this decreases to 15.6 per 100,000 if cases of NF are excluded. Radiation treatment therefore increases the risk by approximately 10 times in non-NF cases.

\section{Acknowledgments}

We thank Drs. Vasileios Kontopoulos and Anthanasios Kontopoulos for the provision of clinical material.

\section{Disclosure}

The authors report no conflict of interest concerning the materials or methods used in this study or the findings specified in this paper.

Author contributions to the study and manuscript preparation include the following. Conception and design: Torrens. Acquisition of data: Torrens, Seferis, Psichidis. Analysis and interpretation of data: Torrens, Paraskevopoulou. Drafting the article: Torrens. Critically revising the article: Paraskevopoulou. Reviewed submitted version of manuscript: Seferis, Psichidis. Approved the final version of the manuscript on behalf of all authors: Torrens.

\section{References}

1. Acoustic Neuroma Association: 2012 ANA Patient Survey. (https://www.anausa.org/resources/patient-surveys/20072008-survey-results1/doc_download/230-2012-surveyresults) [Accessed August 24, 2014]

2. Akamatsu Y, Murakami K, Watanabe M, Jokura H, Tominaga $\mathrm{T}$ : Malignant peripheral nerve sheath tumor arising from benign vestibular schwannoma treated by gamma knife radiosurgery after two previous surgeries: a case report with surgical and pathological observations. World Neurosurg 73: 751-754, 2010

3. Babu R, Sharma R, Bagley JH, Hatef J, Friedman AH, Adamson C: Vestibular schwannomas in the modern era: epidemiology, treatment trends, and disparities in management. Clinical article. J Neurosurg 119:121-130, 2013

4. Bari ME, Forster DM, Kemeny AA, Walton L, Hardy D, Anderson JR: Malignancy in a vestibular schwannoma. Report of a case with central neurofibromatosis, treated by both stereotactic radiosurgery and surgical excision, with a review of the literature. Br J Neurosurg 16:284-289, 2002

5. Baser ME, Evans DG, Jackler RK, Sujansky E, Rubenstein A: Neurofibromatosis 2, radiosurgery and malignant nervous system tumours. Br J Cancer 82:998, 2000

6. Best PV: Malignant triton tumour in the cerebellopontine angle. Report of a case. Acta Neuropathol 74:92-96, 1987

7. Cahan WG, Woodard HQ, Higinbotham NL, Stewart FW, Coley BL: Sarcoma arising in irradiated bone: report of eleven cases. 1948. Cancer 82:8-34, 1998 
8. Caporlingua F, Lapadula G, Antonelli M, Missori P: Pleomorphic rhabdomyosarcoma of the cerebellopontine angle in an adult: a review of literature. BMJ Case Rep 2014: bcr2013203257, 2014

9. Cardoso AC, Fernandes YB, Ramina R, Borges G: Acoustic neuroma (vestibular schwannoma): surgical results on 240 patients operated on dorsal decubitus position. Arq Neuropsiquiatr 65:605-609, 2007

10. Carlson ML, Babovic-Vuksanovic D, Messiaen L, Scheithauer BW, Neff BA, Link MJ: Radiation-induced rhabdomyosarcoma of the brainstem in a patient with neurofibromatosis type 2. Case report. J Neurosurg 112:81-87, 2010 (Erratum in $\mathbf{J}$ Neurosurg 112:209, 2010)

11. Chen L, Mao Y, Chen H, Zhou LF: Diagnosis and management of intracranial malignant peripheral nerve sheath tumors. Neurosurgery 62:825-832, 2008

12. Comey CH, McLaughlin MR, Jho HD, Martinez AJ, Lunsford LD: Death from a malignant cerebellopontine angle triton tumor despite stereotactic radiosurgery. Case report. J Neurosurg 89:653-658, 1998

13. Demetriades AK, Saunders N, Rose P, Fisher C, Rowe J, Tranter R, et al: Malignant transformation of acoustic neuroma/vestibular schwannoma 10 years after gamma knife stereotactic radiosurgery. Skull Base 20:381-387, 2010

14. Earls JP, Robles HA, McAdams HP, Rao KC: General case of the day. Malignant melanotic schwannoma of the eighth cranial nerve. Radiographics 14:1425-1427, 1994

15. Gong L, Liu XY, Zhang WD, Han XJ, Yao L, Zhu SJ, et al: A rare case of malignant triton tumor in the cerebellopontine angle. Diagn Pathol 7:43, 2012

16. Gonzalez LF, Lekovic GP, Eschbacher J, Coons S, Spetzler RF: A true malignant schwannoma of the eighth cranial nerve: case report. Neurosurgery 61:E421-E422, 2007

17. Gousias K, Boström J, Kovacs A, Niehusmann P, Wagner I, Kristof R: Factors of influence upon overall survival in the treatment of intracranial MPNSTs. Review of the literature and report of a case. Radiat Oncol 5:114, 2010

18. Gruber B, Petchenik L, Williams M, Thomas C, Luken MG: Malignant vestibular schwannoma. Skull Base Surg 4:227231, 1994

19. Han DH, Kim DG, Chi JG, Park SH, Jung HW, Kim YG: Malignant triton tumor of the acoustic nerve. Case report. J Neurosurg 76:874-877, 1992

20. Hanabusa K, Morikawa A, Murata T, Taki W: Acoustic neuroma with malignant transformation. Case report. J Neurosurg 95:518-521, 2001

21. Harada K, Nishizaki T, Adachi N, Suzuki M, Ito H: Pediatric acoustic schwannoma showing rapid regrowth with high proliferative activity. Childs Nerv Syst 16:134-137, 2000

22. Hasegawa T, Kida Y, Kato T, Iizuka H, Kuramitsu S, Yamamoto T: Long-term safety and efficacy of stereotactic radiosurgery for vestibular schwannomas: evaluation of 440 patients more than 10 years after treatment with Gamma Knife surgery. Clinical article. J Neurosurg 118:557-565, 2013

23. Hernanz-Schulman M, Welch K, Strand R, Ordia JI: Acoustic neuromas in children. AJNR Am J Neuroradiol 7:519-521, 1986

24. Higami Y, Shimokawa I, Kishikawa M, Okimoto T, Ohtani $\mathrm{H}$, Tomita $\mathrm{M}$, et al: Malignant peripheral nerve sheath tumors developing multifocally in the central nervous system in a patient with neurofibromatosis type 2 . Clin Neuropathol 17:115-120, 1998

25. Ho SY, Kveton JF: Rapid growth of acoustic neuromas after stereotactic radiotherapy in type 2 neurofibromatosis. Ear Nose Throat J 81:831-833, 2002

26. Hong W, Cheng H, Wang X, Hu X, Feng C: Study of malignant peripheral nerve sheath tumor in cerebellopontine angle. J Craniofac Surg 25:699-701, 2014

27. Inoue YZ, Frassica FJ, Sim FH, Unni KK, Petersen IA,
McLeod RA: Clinicopathologic features and treatment of postirradiation sarcoma of bone and soft tissue. J Surg Oncol 75:42-50, 2000

28. Karami KJ, Kelkar PS, Verdon MP, Grills IS, Bojrab DI, Pieper DR: Malignant peripheral nerve sheath tumor of the vestibulocochlear nerve and brainstem: multimodality treatment with survival of 27 months. A case report and review of the literature. Neurosurgery 69:E1152-E1165, 2011

29. Kubo O, Chernov M, Izawa M, Hayashi M, Muragaki Y, Maruyama T, et al: Malignant progression of benign brain tumors after gamma knife radiosurgery: is it really caused by irradiation? Minim Invasive Neurosurg 48:334-339, 2005

30. Kudo M, Matsumoto M, Terao H: Malignant nerve sheath tumor of acoustic nerve. Arch Pathol Lab Med 107:293-297, 1983

31. Kuzmik GA, Michaelides EM, Chiang VL, Nonaka Y, Fukushima T, Vortmeyer AO, et al: Rapidly progressive epithelioid malignant peripheral nerve sheath tumor of the vestibular nerve. Otol Neurotol 34:1739-1742, 2013

32. L'heureux-Lebeau B, Saliba I: Updates on the diagnosis and treatment of intracranial nerve malignant peripheral nerve sheath tumors. Onco Targets Ther 6:459-470, 2013

33. Leksell Gamma Knife Society: Leksell Gamma Knife: Indications Treated 1991 to 2012, 68\%-100\% of Sites Reporting. Stockholm: Leksell Gamma Knife Society, 2013

34. Maeda M, Jozaki T, Baba S, Muro H, Shirasawa H, Ichihashi T: Malignant nerve sheath tumor with rhabdomyoblastic differentiation arising from the acoustic nerve. Acta Pathol Jpn 43:198-203, 1993

35. Maire JP, Huchet A, Milbeo Y, Darrouzet V, Causse N, Célérier $\mathrm{D}$, et al: Twenty years' experience in the treatment of acoustic neuromas with fractionated radiotherapy: a review of 45 cases. Int J Radiat Oncol Biol Phys 66:170-178, 2006

36. Markou K, Eimer S, Perret C, Huchet A, Goudakos J, Liguoro $\mathrm{D}$, et al: Unique case of malignant transformation of a vestibular schwannoma after fractionated radiotherapy. Am J Otolaryngol 33:168-173, 2012

37. Matsumoto M, Sakata Y, Sanpei K, Onagi A, Terao H, Kudo M: [Malignant schwannoma of acoustic nerve: a case report.] No Shinkei Geka 18:59-62, 1990 (Jpn)

38. McEvoy AW, Kitchen ND: Rapid enlargement of a vestibular schwannoma following gamma knife treatment. Minim Invasive Neurosurg 46:254-256, 2003

39. McLean CA, Laidlaw JD, Brownbill DS, Gonzales MF: Recurrence of acoustic neurilemoma as a malignant spindle-cell neoplasm. Case report. J Neurosurg 73:946-950, 1990

40. Miller RT, Sarikaya H, Sos A: Melanotic schwannoma of the acoustic nerve. Arch Pathol Lab Med 110:153-154, 1986

41. Mrak RE, Flanigan S, Collins CL: Malignant acoustic schwannoma. Arch Pathol Lab Med 118:557-561, 1994

42. Muracciole X, Cowen D, Régis J: [Radiosurgery and brain radio-induced carcinogenesis: update.] Neurochirurgie 50: 414-420, 2004 (Fr)

43. Newell K, Pollack A: Bilateral cranial nerve VII-VIII malignant peripheral nerve sheath tumors mimicking neurofibromatosis type 2. J Neuropathol Exp Neurol 71:593, 2012 (Abstract)

44. Norén G: Long-term complications following gamma knife radiosurgery of vestibular schwannomas. Stereot Funct Neurosurg 70 Suppl:165-173, 1998

45. Pollock BE, Lunsford LD, Kondziolka D, Sekula R, Subach BR, Foote RL, et al: Vestibular schwannoma management. Part II. Failed radiosurgery and the role of delayed microsurgery. J Neurosurg 89:949-955, 1998

46. Puataweepong P, Janwityanujit T, Larbcharoensub N, Dhanachai M: Radiation-induced peripheral malignant nerve sheath tumor arising from vestibular schwannoma after linac-based stereotactic radiation therapy: a case report and review of literatures. Case Rep Med 2012:648191, 2012 
47. Rowe J, Grainger A, Walton L, Silcocks P, Radatz M, Kemeny A: Risk of malignancy after gamma knife stereotactic radiosurgery. Neurosurgery 60:60-66, 2007

48. Saito T, Oki S, Mikami T, Kawamoto Y, Yamaguchi S, Kuwamoto K, et al: [Malignant peripheral nerve sheath tumor with divergent cartilage differentiation from the acoustic nerve: case report.] No To Shinkei 52:734-739, 2000 (Jpn)

49. Samii M, Matthies C: Management of 1000 vestibular schwannomas (acoustic neuromas): surgical management and results with an emphasis on complications and how to avoid them. Neurosurgery 40:11-23, 1997

50. Scheithauer BW, Erdogan S, Rodriguez FJ, Burger PC, Woodruff JM, Kros JM, et al: Malignant peripheral nerve sheath tumors of cranial nerves and intracranial contents: a clinicopathologic study of 17 cases. Am J Surg Pathol 33:325-338, 2009

51. Schmitt WR, Carlson ML, Giannini C, Driscoll CL, Link MJ: Radiation-induced sarcoma in a large vestibular schwannoma following stereotactic radiosurgery: case report. Neurosurgery 68:E840-E846, 2011

52. Shahinian HK, Ra Y: 527 fully endoscopic resections of vestibular schwannomas. Minim Invasive Neurosurg 54:61-67, 2011

53. Shin M, Ueki K, Kurita H, Kirino T: Malignant transformation of a vestibular schwannoma after gamma knife radiosurgery. Lancet 360:309-310, 2002

54. Son EI, Kim IM, Kim SP: Vestibular schwannoma with malignant transformation: a case report. J Korean Med Sci 16: 817-821, 2001

55. Stangerup SE, Tos M, Thomsen J, Caye-Thomasen P: True incidence of vestibular schwannoma? Neurosurgery 67:13351340,2010

56. Suresh TN, Mahadevan A, Chandrashekhar Sagar B, Santosh V, Yasha TC, Shankar SK: Unusual case of multiple cellular and malignant schwannomas of the cranial and spinal nerves. Clin Neuropathol 22:23-29, 2003
57. Tanbouzi Husseini S, Piccirillo E, Taibah A, Paties CT, Rizzoli R, Sanna M: Malignancy in vestibular schwannoma after stereotactic radiotherapy: a case report and review of the literature. Laryngoscope 121:923-928, 2011

58. Thomsen J, Mirz F, Wetke R, Astrup J, Bojsen-Møller M, Nielsen E: Intracranial sarcoma in a patient with neurofibromatosis type 2 treated with gamma knife radiosurgery for vestibular schwannoma. Am J Otol 21:364-370, 2000

59. Van Rompaey K, Michotte A, Ampe B, Moens M, Ates R, Chaskis C, et al: Malignant transformation of a vestibular schwannoma after radiosurgery. Surg Neurol 71:145, 2009 (Abstract)

60. Wei C, Heman-Ackah SE, Newman K, Zagzag D, Golfinos JG, Roland JT Jr: Temporal bone histopathology case of the month: malignant peripheral nerve sheath tumor arising within vestibular schwannoma. Otol Neurotol 33:e83-e84, 2012

61. Wilkinson JS, Reid H, Armstrong GR: Malignant transformation of a recurrent vestibular schwannoma. J Clin Pathol 57:109-110, 2004

62. Yanamadala V, Williamson RW, Fusco DJ, Eschbacher J, Weisskopf P, Porter RW: Malignant transformation of a vestibular schwannoma after gamma knife radiosurgery. World Neurosurg 79:593.e1-593.e8, 2013

63. Yang T, Rockhill J, Born DE, Sekhar LN: A case of highgrade undifferentiated sarcoma after surgical resection and stereotactic radiosurgery of a vestibular schwannoma. Skull Base 20:179-183, 2010

Manuscript submitted June 12, 2014.

Accepted July 17, 2014.

Please include this information when citing this paper: DOI: 10.3171/2014.7.GKS141311.

Address correspondence to: Michael Torrens, F.R.C.S., Department of Neurosurgery, Hygeia Hospital, 4 Erythrou Stavrou, Maroussi, 15123 Athens, Greece. email: m.torrens@hygeia.gr. 